Arq. Bras. Med. Vet. Zootec., v.69, n.4, p.802-806, 2017

\title{
Citocentrifugação e métodos convencionais na citologia uterina de éguas em estro e diestro
}

[Cytocentrifugation and conventional methods in endometrial cytology of estrus and diestrus mares]

\author{
M.L.N. Jorge ${ }^{1}$, C.M.B. Orlandi ${ }^{2}$, A.E. Santana ${ }^{1}$ \\ ${ }^{1}$ Universidade Estadual Paulista "Júlio de Mesquita Filho" - Unesp - Jaboticabal, SP \\ ${ }^{2}$ Universidade Brasil - Descalvado, SP
}

\begin{abstract}
RESUMO
A citologia uterina consiste em método prático e eficiente para o diagnóstico de afecções uterinas na égua, contribuindo para a conduta terapêutica e o prognóstico quanto à fertilidade das fêmeas. Assim, o objetivo deste trabalho foi comparar diferentes técnicas de coleta de material para citologia uterina em éguas, a fim de se verificarem possíveis diferenças qualitativas e quantitativas e a praticidade na execução das metodologias. Para tanto, 12 éguas multíparas foram submetidas ao exame citológico uterino, durante o estro e o diestro, por meio de escova ginecológica e lavado uterino de baixo volume. Com esse ensaio, observou-se que não houve diferença significativa $(\mathrm{P}>0,05)$ no resultado da citologia uterina entre as diferentes técnicas avaliadas. No entanto, quando comparadas as fases do ciclo estral, houve uma diferença significativa $(\mathrm{P}<0,05)$ quanto ao percentual médio de polimorfonucleares neutrófilos, sendo de $8,07 \pm 2,80$ no estro e de $1,55 \pm 0,28$ no diestro. Conclui-se, desse modo, que as técnicas estudadas apresentaram resultados igualmente eficazes para detecção de neutrófilos ao exame citológico do útero em ambas as fases avaliadas do ciclo estral, apesar de, na fase de estro, a detecção de maior percentual de neutrófilos possibilitar um diagnóstico e um prognóstico mais precoces de endometrite e, portanto, uma conduta terapêutica mais adequada.
\end{abstract}

Palavras-chave: equino, endometrite, neutrófilos, citologia e útero

\begin{abstract}
The endometrial cytology consists in an efficient and practical method for the diagnosis of uterine disorders in mares, contributing for therapeutic conduct and prognostic evaluation regarding the females' fertility. Therefore, the aim of this study was to compare different techniques of material sampling for endometrial cytology in mares, in order to verify possible qualitative and quantitative differences in the practicality of implementation of this methodology. Twelve multiparous mares underwent an endometrial cytological exam, during estrus and diestrus, by means of a cytobrush and a low-volume uterine flush. With this test, no statistical difference was observed $(P>0.05)$ regarding the result of endometrial cytology between the evaluated techniques. However, in comparison to the estrous cycle's phases, a significant difference was verified $(P<0.05)$ on the average percentage of polymorphonuclear neutrophils: $8.07 \pm 2.80$ in estrus and $1.55 \pm 0.28$ in diestrus. Thus, we conclude that the studied techniques presented equally effective results for the detection of neutrophils in the cytological exam for both evaluated stages of the estrous cycle, whereas in estrus phase, the detection of a higher percentage of neutrophils allows a more precocious diagnostic and prognostic of endometritis and, therefore, a more adequate therapeutic approach.
\end{abstract}

Keywords: endometritis, equine, neutrophils, cytology and uterus

Recebido em 27 de outubro de 2016

Aceito em 3 de dezembro de 2016

E-mail: marianalnj@hotmail.com 


\section{INTRODUÇÃO}

A obtenção de amostras uterinas de éguas, seja por citologia, seja por biópsia endometrial, é realizada rotineiramente para o diagnóstico de afecções uterinas. A citologia uterina é uma ferramenta muito utilizada para avaliar a inflamação uterina por meio da detecção de polimorfonucleares neutrófilos (Card, 2005), consistindo em um método prático quanto à sua execução e rápido quanto à obtenção dos resultados, o que facilita a conduta terapêutica em éguas destinadas à reprodução ou o descarte de éguas receptoras em programas de transferência de embriões.

A coleta de material uterino para o exame citológico é comumente realizada por meio de escova ginecológica, "swab" uterino ou lavado uterino de baixo volume (Bohn et al., 2014).

Embora estudos relatem a sensibilidade e especificidade de diferentes métodos para diagnóstico de inflamação uterina (Riddle et al., 2007; Overbeck et al., 2011) em éguas inférteis (Cocchia et al., 2012) e saudáveis (Bohn et al., 2014), não há relatos quanto à utilização da citocentrifugação do lavado uterino de baixo volume como método de preparação citológica uterina em éguas.

O uso da citocentrifugação do lavado uterino de baixo volume foi empregado, neste estudo, com o propósito de concentrar as células sobre a lâmina de microscopia, sendo uma maneira inovadora e eficiente de otimizar a interpretação da lâmina obtida pelo lavado uterino, podendo contribuir para a eficácia na interpretação do diagnóstico citológico.

O exame citológico pode ser realizado em diferentes fases do ciclo estral da égua, de acordo com a necessidade do veterinário e/ou proprietário. Porém, Reiswig et al. (1993) relataram diferença significativa na proporção de células epiteliais livres e aglomeradas na citologia uterina de éguas coletadas no estro e no diestro. Além disso, a qualidade e a quantidade do material coletado variam entre os métodos de coleta, podendo, consequentemente, alterar os resultados (Kozdrowski et al., 2015).

Assim, o objetivo deste estudo foi comparar a citologia uterina em éguas durante as fases de estro e diestro, por meio de escova ginecológica, lavado uterino de baixo volume $\mathrm{e}$ citocentrifugação dele. Com isso, buscou-se identificar possíveis diferenças qualitativas e quantitativas com o uso das metodologias citadas, assim como verificar a praticidade na execução das técnicas em éguas cíclicas.

\section{MATERIAL E MÉTODOS}

Doze éguas entre cinco e 15 anos de idade, peso corporal de 350 a $450 \mathrm{~kg}$, que não apresentaram prenhez na última estação reprodutiva e ciclicidade regular, foram mantidas em piquetes na Universidade Estadual Paulista Júlio de Mesquita Filho.

As éguas receberam feno, ração, sal mineral e água ad libitum, sendo utilizadas de acordo com as normas de bem-estar animal estabelecidas pela Comissão de Ética da FCAV/Unesp, Campus de Jaboticabal, protocolo de aprovação número: 006757/12.

Um ciclo estral de cada égua foi utilizado, com dois momentos de coletas (estro e diestro) no mesmo ciclo, totalizando 24 coletas uterinas. Setenta e duas preparações citoscópicas foram confeccionadas por meio de técnicas distintas: escova ginecológica $(\mathrm{n}=24)$, lavado de baixo volume convencional $(n=24)$ e citocentrifugação do lavado uterino $(\mathrm{n}=24)$.

A regularidade na ciclicidade das éguas antes e durante o experimento foi determinada por meio de exame ginecológico, com ênfase no comportamento sexual, na palpação transretal e na ultrassonografia (transdutor linear $5 \mathrm{MhZ}$, Mindray ${ }^{\circledR}$ ). Foram incluídas no experimento éguas que apresentaram ciclicidade regular com pelo menos um intervalo interovulatório determinado por meio das avaliações ginecológicas acima citadas.

As éguas foram submetidas às técnicas de citologia uterina durante o estro e o diestro, sendo estabelecidos critérios para inclusão delas nas respectivas fases: estro, considerou-se o comportamento de cio positivo, edema uterino de grau 2 a 3 (classificação 1- 5; Samper, 2009) e presença de folículos ovarianos medindo entre 28 e $38 \mathrm{~mm}$ de diâmetro, ambos detectados por meio de ultrassonografia transretal (Brinsko et al., 2011); e diestro, quando identificado o corpo 
lúteo (CL), seis a nove dias após a detecção da ovulação, por meio de ultrassonografia transretal, momento em que as coletas de material uterino foram realizadas. $\mathrm{O}$ tônus uterino e cervical foi determinado por meio de exame transretal, seguido de ultrassonografia, para verificação do CL, assim como a ecogenicidade e possível presença de fluido no lúmen uterino.

O exame citológico foi realizado por meio de escova ginecológica e lavado uterino de baixo volume. A escova ginecológica era acoplada à pinça de citologia; após a introdução da extremidade da pinça de citologia dentro do lúmen uterino, esta era posicionada no corpo do útero, e, uma vez em contato com a superfície uterina, a escova ginecológica era exposta e girada cinco vezes para a obtenção do material. Após a coleta do material, a pinça de citologia era removida, e o material da escova transferido para uma lâmina. A lâmina era seca e, posteriormente, submetida à coloração.

Já para obtenção do lavado uterino de baixo volume, utilizou-se o sistema fechado (três vias) de lavagem uterina, por meio de sonda Bivona ${ }^{\circledR}$ (Partnar Animal Health, EUA), e condutos siliconizados. Para tanto, infundiram-se aproximadamente $100 \mathrm{~mL}$ de solução fisiológica $\mathrm{e}$, posteriormente, realizou-se massagem do útero por via transretal para auxiliar a recuperação do volume de solução infundida.

Na técnica de lavado uterino de baixo volume convencional, a solução uterina recuperada em tubo graduado foi homogeneizada $\mathrm{e}$ imediatamente transferida para tubos de $50 \mathrm{~mL}$ tipo Falcon, sendo armazenada a $4^{\circ} \mathrm{C}$, para posterior centrifugação (400 rpm por 10 minutos) e confecção das preparações citoscópicas. Após a centrifugação, o sobrenadante foi descartado, remanescendo $2 \mathrm{~mL}$ do "pellet" para homogeneização e extensão sobre a superfície da lâmina e posterior coloração.

Na técnica de citocentrifugação do lavado, uma alíquota do material submetido à centrifugação anterior foi citocentrifugada a 1200rpm, durante cinco minutos (citocentrífuga FANEM, Mod. 218, Brasil), originando duas áreas microcirculares sobre a preparação citoscópica.
Todas as preparações sobre lâminas foram confeccionadas e submetidas à coloração rápida Panótico ${ }^{\circledR}$ (Laborclin, Brasil), seguindo as indicações do fabricante.

À avaliação microscópica, contou-se um total de 200 células (epiteliais e inflamatórias) por campo microscópico de imersão (aumento de 1000x) e, com base nisso, estabeleceu-se a porcentagem de polimorfonucleares neutrófilos.

A classificação dos polimorfonucleares neutrófilos ao exame microscópico deu-se em valores relativos (\%), por meio do qual se estabeleceu o grau de inflamação endometrial (GI) segundo a classificação: 0 a 3 - normal no estro; >3 a 10 - endometrite leve; >10 a $15-$ endometrite leve a moderada; $>15$ a $30-$ endometrite moderada; $>30$ a 50 - endometrite moderada a severa; $>50$ a 75 - endometrite severa; >75 - endometrite muito severa (Adaptada de Couto e Hughes, 1984).

Os dados foram analisados utilizando-se ANOVA, seguido do teste Tukey de comparação de médias, tendo $\mathrm{P}<0,05$ como significativo, segundo os procedimentos do pacote estatístico AgroEstat - Sistema para Análises Estatísticas de Ensaios Agronômicos (Barbosa e Maldonado Júnior, 2008).

\section{RESULTADOS E DISCUSSÃO}

O percentual médio de polimorfonucleares neutrófilos não diferiu $(\mathrm{P}=0,6719)$ entre as técnicas tanto no estro quanto no diestro (Tab. 1), mostrando que as três técnicas foram eficazes na detecção de neutrófilos.

Tabela 1. Percentual médio \pm erro-padrão da média $(\mu \pm$ EPM\% $)$ de polimorfonucleares neutrófilos em amostras obtidas por diferentes técnicas no estro e no diestro em éguas cíclicas

\begin{tabular}{ccc} 
Técnica & $\begin{array}{c}\text { Estro } \\
(\mu \pm \text { EPM\% })\end{array}$ & $\begin{array}{c}\text { Diestro } \\
(\mu \pm \text { EPM\% })\end{array}$ \\
\hline $\begin{array}{c}\text { Escova } \\
\text { ginecológica }\end{array}$ & $9,73 \pm 4,41$ & $1,57 \pm 2,02$ \\
$\begin{array}{c}\text { Centrifugação } \\
\text { convencional }\end{array}$ & $5,97 \pm 2,06$ & $1,29 \pm 2,16$ \\
Citocentrifugação & $8,49 \pm 3,10$ & $1,77 \pm 1,87$ \\
\hline
\end{tabular}


Considerando-se a fase do ciclo estral,quando realizada durante o estro, a técnica de escova ginecológica e a alíquota do lavado uterino submetida à citocentrifugação permitiram a classificação de GI de leve a moderada, fato não verificado no lavado uterino submetido apenas à centrifugação convencional. Já na fase de diestro, as três técnicas permitiram a classificação das éguas como portadoras de endometrite de grau leve, apresentando a escova ginecológica e a alíquota do lavado uterino submetida à citocentrifugação maior percentual médio de polimorfonucleares neutrófilos.

A citocentrifugação é uma técnica bastante utilizada em lavados broncoalveolares de equinos, por promover a concentração das células e preservar sua morfologia, facilitando a avaliação da lâmina (Biava et al., 2005). No presente estudo, a citocentrifugação contribuiu para a eficácia na interpretação do diagnóstico citológico do lavado uterino, caracterizando-se pela concentração das células na amostra.

Como observado por Bohn et al. (2014), para a execução do lavado uterino são necessárias pelo menos duas pessoas; já para a coleta de material uterino pela escova ginecológica, uma única pessoa é capaz de o fazer. A obtenção de material uterino pela escova ginecológica é mais prática e permite resultados mais rápidos, haja vista que o material não passa por processamento laboratorial (Alvarenga e Mattos, 1991). Embora a amostra seja obtida de um único ponto do endométrio, o resultado é representativo da condição uterina, sendo a técnica de escolha para a avaliação da condição uterina de éguas a campo (Overbeck et al., 2011; Cocchia et al., 2012).

Em bovinos, a citologia uterina por meio de escova ginecológica é bastante utilizada e se mostrou superior à técnica de lavado uterino de baixo volume quanto à praticidade, integridade celular e detecção de polimorfonucleares (Kasimanickam et al., 2005). Segundo Pascottini et al. (2015), não existe uma técnica ideal de citologia uterina; cada técnica apresenta suas vantagens e desvantagens, embora a citologia uterina por meio de escova ginecológica seja a técnica de eleição em bovinos.

O percentual de polimorfonucleares neutrófilos segmentados nas fases de estro e diestro, considerando-se valores médios das três técnicas, apresentou diferença significativa entre as fases $(\mathrm{P}=0,0250)$, como pode ser observado na Tab. 2 .

Tabela 2. Percentual médio \pm erro-padrão da média $(\mu \pm \mathrm{EPM} \%)$ de polimorfonucleares neutrófilos obtidos no estro e no diestro em éguas cíclicas

\begin{tabular}{cc}
\hline Fases do ciclo estral & $\mu \pm$ EPM\% \\
\hline Estro & $8,07 \pm 2,80^{\mathrm{a}}$ \\
Diestro & $1,55 \pm 0,28^{\mathrm{b}}$ \\
\hline
\end{tabular}

Médias com letras distintas na coluna diferem significativamente entre si pelo teste de Tukey $(\mathrm{P}<0,05)$.

A coleta de material no estro permitiu a detecção de um maior percentual de polimorfonucleares neutrófilos do que no diestro, consequentemente a classificação do grau de endometrite das éguas diferiu, sendo leve a moderado no estro e leve no diestro.

Os achados acima citados corroboram a assertiva de que no estro as éguas apresentam uma tendência ao acúmulo de polimorfonucleares neutrófilos nas margens das vênulas em direção ao lúmen uterino e dentro dos capilares (Kenney, 1978), uma vez que, sob influência do estrógeno, a migração de neutrófilos para o lúmen uterino é maior. A hiperemia facilita a entrada de neutrófilos no útero, tal qual asseverado por Evans et al. (1987) e Jones et al. (1991).

Desse modo, quando a égua encontra-se no estro, um percentual de neutrófilos de até $3 \%$ é considerado normal (Couto e Hughes, 1984; Kozdrowski et al., 2015), embora se saliente o fato de não haver um único padrão estabelecido sobre a interpretação dos resultados de citologia uterina, variando entre autores (Card, 2005).

\section{CONCLUSÃO}

As técnicas de escova ginecológica e de lavado uterino de baixo volume empregadas neste estudo não diferiram estatisticamente, deixando antever que uma técnica pode apresentar resultados tão eficazes quanto a outra para detecção de neutrófilos ao exame citológico do útero. De outra parte, observaram-se diferenças estatísticas ao exame citológico quando foram 
comparadas as duas distintas fases do ciclo estral com relação ao percentual médio de neutrófilos. Assim, o exame citológico realizado durante o estro permitiu a detecção de maior percentual de neutrófilos, possibilitando diagnóstico e prognóstico mais precoces de endometrite e conduta terapêutica mais adequada. Em relação às técnicas, a realização do exame citológico por meio de escova ginecológica é mais prática, e os resultados são obtidos mais rapidamente.

\section{AGRADECIMENTOS}

Ao $\mathrm{CNPq} / \mathrm{PIBIC}$, pelo apoio financeiro a esta pesquisa.

\section{REFERÊNCIAS}

ALVARENGA, M.A.; MATTOS, M.C.F.I. Eficiência da escova ginecológica "Cytobrush" na colheita de material endometrial de éguas. Arq. Bras. Med. Vet. Zootec., v.42, p.67-68, 1991.

BARBOSA, J.C.; MALDONADO JUNIOR, W. AgroEstat - sistema para análises estatísticas de ensaios agronômicos. Versão 1.0. 2008.

BIAVA, J.S.; GONÇALVES, R.C.; ZANOTTO, G.M. et al. Uso da citocentrífuga e colorações especiais no exame citológico do lavado broncoalveolar em cavalos. Rev. Acad. Curitiba, v.3, p.47-50, 2005.

BOHN, A.A.; FERRIS, R.A.; MCCUE, P.M. Comparison of equine endometrial cytology samples collected with uterine swab, uterine brush, and lowvolume lavage from healthy mares. Vet. Clin. Pathol., v.43, p.594-600, 2014.

BRINSKO, S.P.; BLANCHARD, T.L.; VARNER, D.D. et al. Reproductive physiology of the nonpregnant mare. In: BRINSKO, S.P. (Ed.). Manual of equine reproduction. 3.ed. Maryland Heights: Mosby Elsevier, 2011. p.10-18.

CARD, C. Post-breeding inflammation and endometrial cytology in mares. Theriogenology, v.64, p.580-588, 2005.

COCCHIA, N.; PACIELLO, O.; AULETTA, L. et al. Comparison of the cytobrush, cottonswab, and lowvolume uterine flush techiniques to evaluate endometrial cytology for diagnosing endometritis in chronically infertile mares. Theriogenology, v.77, p.89-98, 2012.
COUTO, M.A.; HUGHES, J.P. Techniques and interpretation of cervical and endometrial cytology in the mare. Equine Vet. Sci., v.4, p.265-273, 1984.

EVANS, M.J.; HAMER, J.M.; GASON, L.M.; IRVINE, A.C. Factors affecting uterine clearance of inoculated materials in mares. J. Reprod. Fertil. Suppl., v.35, p.327-342, 1987.

JONES, D.M.; FIELDEN, E.D.; CARR, D.H. Some physiological and pharmacological factors affecting uterine motility as measured by electromyography in the mare. J. Reprod. Fertil. Suppl., v.44, p.357-358, 1991.

KASIMANICKAM, R.; DUFFIELD, T.F.; FOSTER, R.A. et al. A comparison of the cytobrush and uterine lavage techniques to evaluate endometrial cytology in clinically normal postpartum dairy cows. Can. Vet. J., v.46, p.255-259, 2005.

KENNEY, R.M. Cyclic and pathologic changes of the mare endometrium as detected by biopsy, with a note on early embryonic death. J. Am. Vet. Med. Assoc., v.172, p.241-262, 1978.

KOZDROWSKI, R.; SIKORA, M.; BUCZKOWSKA, J. et al. Effects of cycle stage and sampling procedure on interpretation of endometrial cytology in mares. Anim. Reprod. Sci., v.154, p.56-62, 2015.

OVERBECK, W.; WITTE, T.S.; HEUWIESER, W. Comparison of three diagnostic methods to identify subclinical endometritis in mares. Theriogenology, v.75, p.1311-1318, 2011

PASCOTTINI, O.B.; DINI, P.; HOSTENS, M. et al. A novel cytologic sampling technique to diagnose subclinical endometritis and comparison of staining methods for endometrial cytology samples in dairy cows. Theriogenology, v.84, p.1438-1446, 2015.

REISWIG, J.D.; THRELFALL, W.R.; ROSOL, T.J. A comparison of endometrial biopsy, culture and cytology during oestrus and dioestrus in the horse. Equine Vet. J., v.25, p.240-241, 1993.

RIDDLE, W.T.; LEBLANC, M.M.; STROMBERG, A.J. Relationships between uterine culture, cytology and pregnancy rates in a thoroughbred practice. Theriogenology, v.68, p.395-402, 2007.

SAMPER, J.C. Uterine edema in the mare. In: (Ed.). Equine breeding management and artificial insemination. 2.ed. Saint Louis: Saunders Elsevier, 2009. p.133-138. 